\title{
Simulation and Analysis of Hybrid Solar E-Rickshaw Using MATLAB
}

\author{
Rohit Kumar* and Ravi Saxena \\ Department of Electrical Engineering, Govind Ballabh Pant University of Agriculture and Technology, India
}

*Corresponding author: Rohit Kumar, Department of Electrical Engineering, Govind Ballabh Pant University of Agriculture and Technology, Pantnagar, Uttarakhand, India

\begin{abstract}
Global efforts towards minimizing greenhouse gas emissions are required to reduce the environmental issues caused by conventional combustion engine vehicles. Alternate clean and green modes of transportation such as electric vehicles are required in place of conventional vehicles. As a cheaper version of electric vehicle, electric rickshaws (popularly known as E-rickshaws or tuk-tuks) are most popular in India. This work deals with the modeling of popular e-rickshaws in MATLAB/Simulink. Software simulations are much helpful for quickly analyzing the distinct features of the electric vehicle, such as aerodynamic design, battery energy density, motor output, curb weight, etc and to visualize the effects on its performance due to variation in various parameters. Therefore, simulations were performed with Simulink model of hybrid solar e-rickshaw and conceptual solar e-rickshaw model with heterogeneous battery packs. The simulation results favor the possibility of implementing simultaneous battery packs at a reasonable cost price.
\end{abstract}

Keywords: Solar hybrid E-rickshaw; MATLAB; Simulation; Tuk-tuk

\section{Introduction}

Electric vehicles are now in revolutionary phase in India, but not so significantly in cars [1-2]. There are approximately 1.5 million electric rickshaws in India in comparison to 1.35 million electric rickshaws in China. Electric rickshaws (popularly known as

e-rickshaws or tuk-tuks) are popular in several cities of India since 2008 as a result of their low fuel cost, and less human effort compared to pedal rickshaws. They are well accepted as an alternative to combustion engine-powered rickshaws and pedal rickshaw [3].

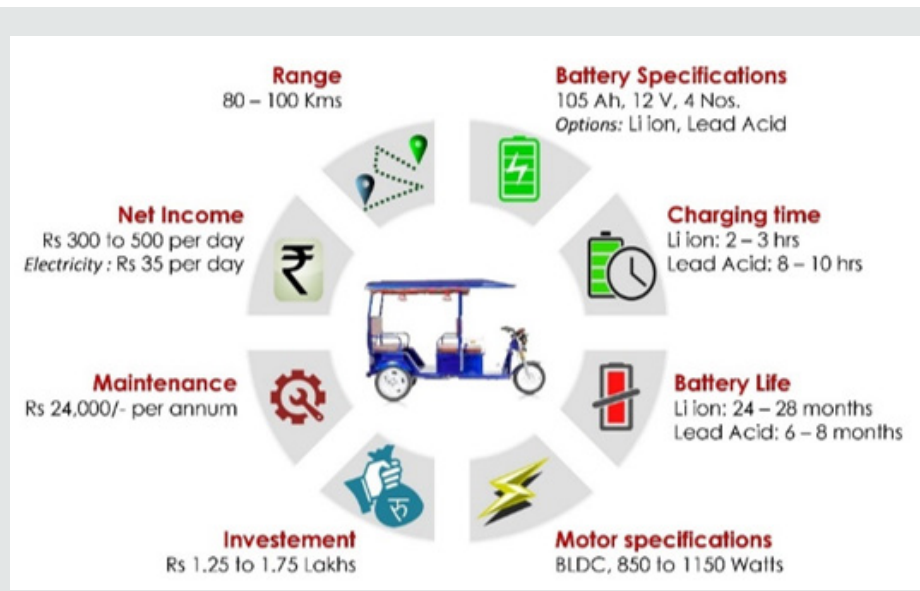

Figure 1: An Illustration of E-rickshaw specifications, investment and net-income. 
The electric rickshaws are powered by brushless dc motors ranging from 850-1150 watts and mostly produced either in China or India. An electric rickshaw offers a cheaper and eco-friendly transport facility to the low-income people [3]. An illustration of E-rickshaw specifications, investment and net-income is shown in Figure 1.

The major reasons for the rise of e-rickshaw are:

1. They require lower investment than an Auto-Rickshaw and quite pleasing daily earnings than cycle rickshaws.

2. They have lower running cost as E-Rickshaw charging is easily available with conventional single phase socket at home and low operating cost model for rickshaw owners.

3. E-Rickshaw is one of the best options for passengers for quick, safe and cost effective last mile connectivity.

4. They provide mass scale employment and good source of income to the traditional rickshaw puller.

\section{Solar hybrid E-rickshaw}

Solar hybrid electric rickshaw has a solar panel and runs up to $110 \mathrm{~km}$ per charge as an attractive alternative to the combustion engine driven auto-rickshaws. Solar energy is freely available sustainable energy which is converted into electrical energy by silicon plates fitted at the top of auto rickshaw for the sustainable energy future. A solar powered electric rickshaw provides a cheapest, cost effective, silent and pollution-free public transport for both rural and urban areas of India [3-4].

\section{Methodology}

Solar Hybrid E-rickshaws are potential alternative in e-rickshaw segment owing to its extended range capability. For the purpose of understanding the concept of Solar Hybrid E-rickshaw, simulation and modeling is performed in MATLAB. Solar Hybrid E-rickshaw is easily analyzed by grouping models of different component namely E-rickshaw body, Solar Panel, MPPT controller, Battery Pack, BLDC Motor drive and display as shown in Figure 2 [5-8].

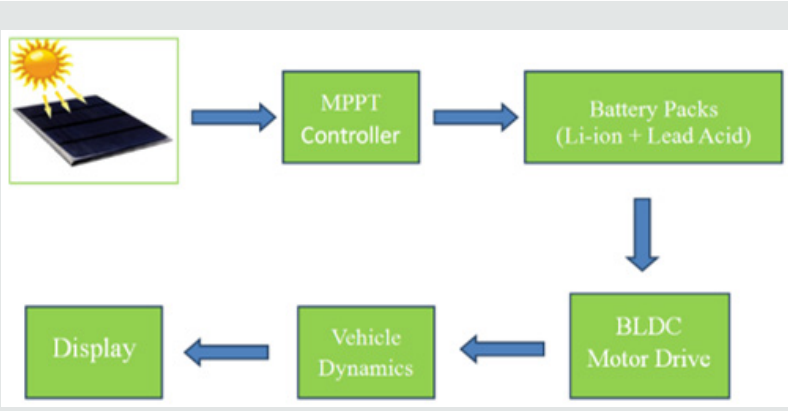

Figure 2: Block Diagram for Solar Hybrid E-rickshaw.

\section{Technical specifications}

For modeling, solar panel parameters were taken as Table 1 and vehicle dynamics were taken as Table 2. The solar panel characteristic I-V and P-V curves are illustrated in Figure 3 and the SIMULINK model of solar hybrid E-rickshaw is shown in Figure 4 and the vehicle dynamics are represented in Figure 5.

Table 1: Solar Panel Parameters.

\begin{tabular}{|c|c|c|}
\hline S. No. & Vehicle Model Parameter & Values \\
\hline 1 & Max Power (watts) & 300 \\
\hline 2 & Open circuit voltage Voc (V) & 56 \\
\hline 3 & Short-circuit current Isc (A) & 6.5 \\
\hline 4 & Temperature coefficient of Voc (\%/deg. C) & -0.36101 \\
\hline 5 & Temperature coefficient of Isc (\%/deg.C) & 0.10199 \\
\hline
\end{tabular}

Table 2: E-rickshaw Dynamics.

\begin{tabular}{|c|c|c|}
\hline S. No. & Vehicle Model Parameter & Values \\
\hline 1 & Payload [kg] & 300 \\
\hline 2 & Gross Weight (m) [kg] & 700 \\
\hline 3 & Width $(\mathrm{w})[\mathrm{mm}]$ & 1324 \\
\hline 4 & Height (h) $[\mathrm{mm}]$ & 1510 \\
\hline 5 & Frontal Area $(A)\left[\mathrm{m}^{2}\right]$ & 1.22 \\
\hline 6 & Rolling Resistance Coefficient (urr) & 0.015 \\
\hline 7 & Drag Coefficient (Cd) & 0.33 \\
\hline 8 & Transmission efficiency & 0.95 \\
\hline 9 & Gear ratio (Gratio) & 10 \\
\hline 10 & Gravity acceleration, $(\mathrm{g})\left[\mathrm{m} / \mathrm{s}^{2}\right]$ & 9.81 \\
\hline 11 & Air-density (d) $\left[\mathrm{kg} / \mathrm{m}^{3}\right]$ & 1.25 \\
\hline 12 & Accessories power [watt] & 20 \\
\hline 13 & Solar Panel [watt] & 300 \\
\hline
\end{tabular}
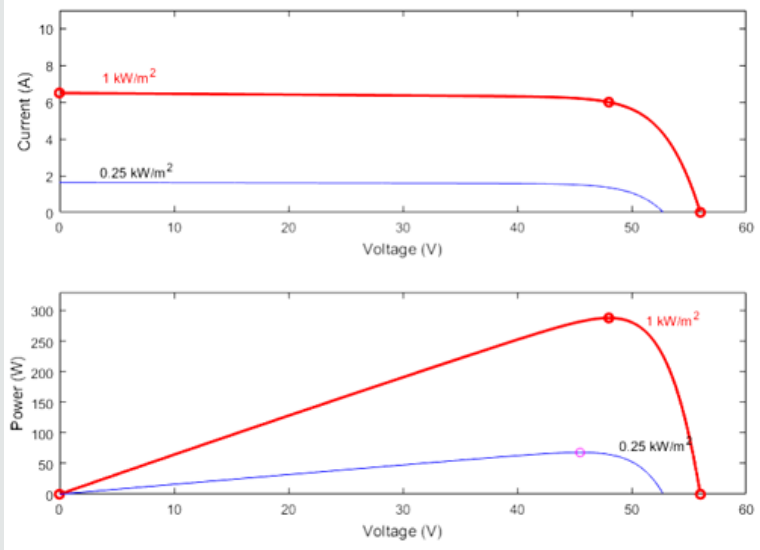

Figure 3: Solar Panel Plots for I-V and P-V curves. 


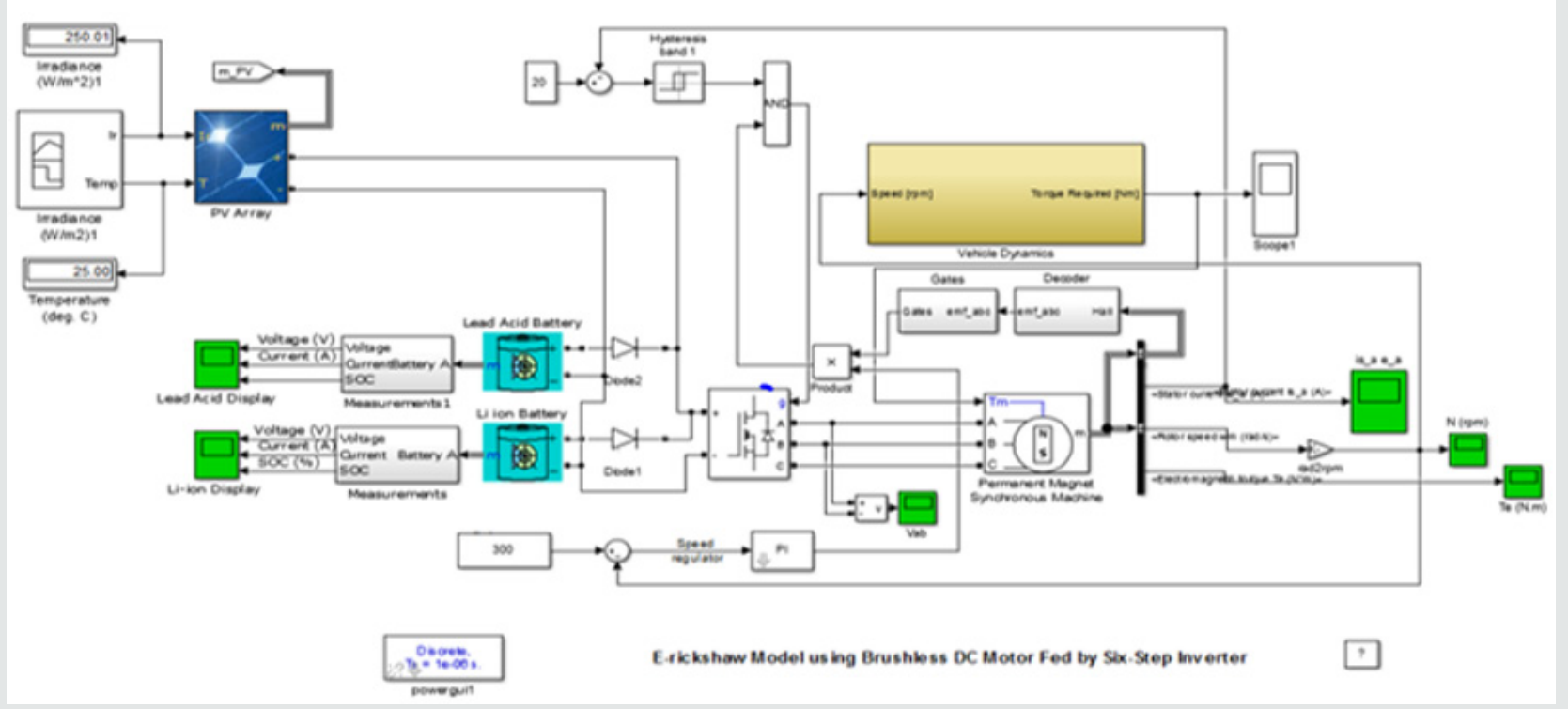

Figure 4: Solar Hybrid E-rickshaw with Li-ion battery pack.

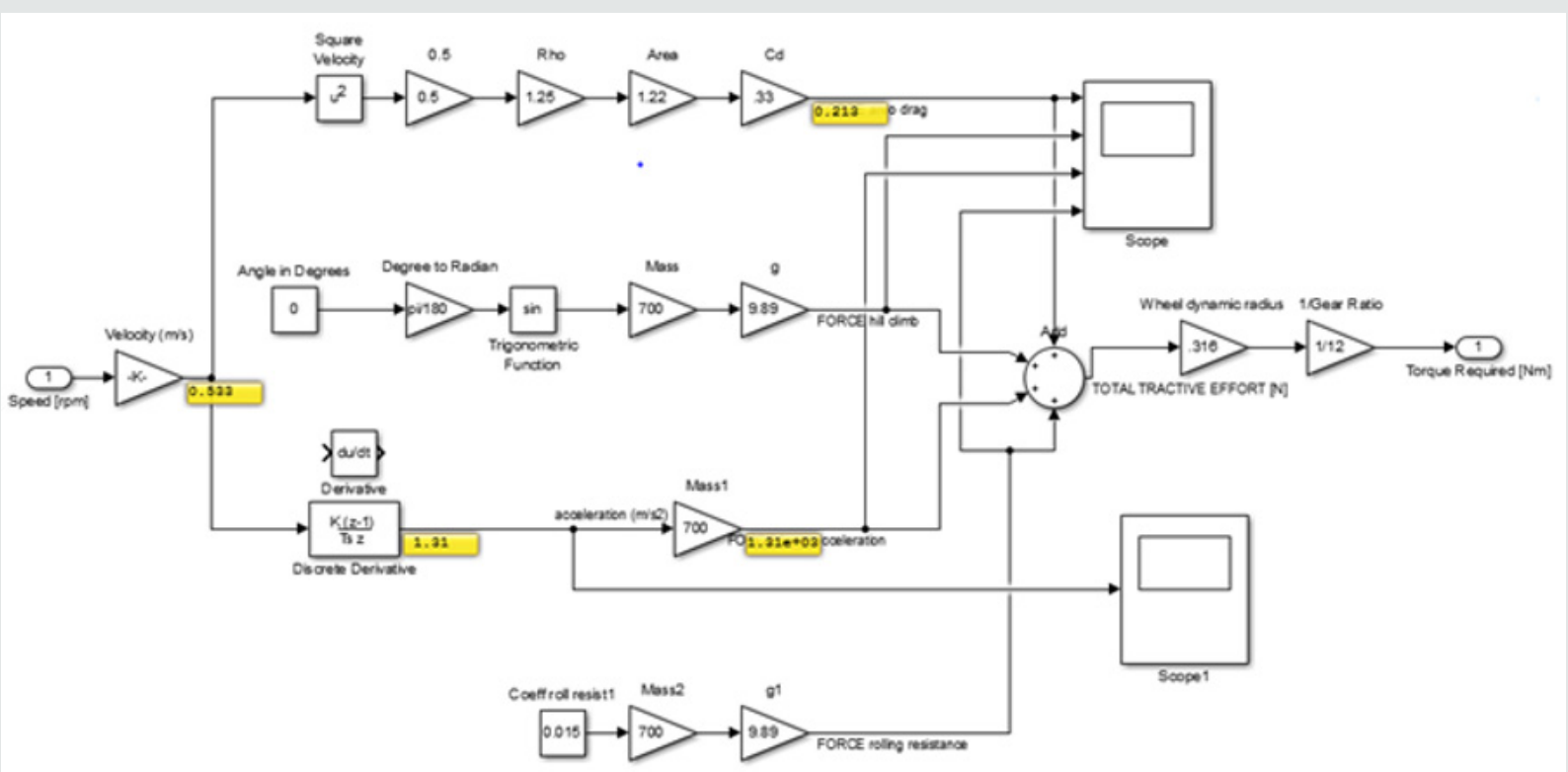

Figure 5: E-rickshaw Dynamics Model.

\section{SIMULINK Models for Solar E-rickshaw with Heterogeneous Battery Packs}

A new concept of using heterogeneous battery packs for electric vehicles is heard now-a-days for the sake of getting good battery life at reasonable price. In this work an attempt is made to visualize the effect of using simultaneous battery packs in Solar Hybrid E-rickshaw. The energy sharing of both the battery packs are monitored and analyzed. The block diagram of Solar Hybrid E-rickshaw with simultaneous battery packs is shown in Figure 6. The Li-ion battery has higher energy density than lead acid battery but costlier in comparison to latter. Therefore in this work an attempt is made to study the possibility of finding a reasonable heterogeneous battery pack for E-rickshaw. The SIMULINK model of solar hybrid E-rickshaw with heterogeneous battery packs is shown in Figure 7. The model consists of sub-blocks of solar panel with MPPT controller, Lead Acid battery pack, Lithium ion battery pack, Permanent Magnet Brushless DC motor, Vehicle dynamics, position sensor, Power Electronics Six-step Inverter and Speed controller. The energy flow under transient operation is simulated and analyzed. 


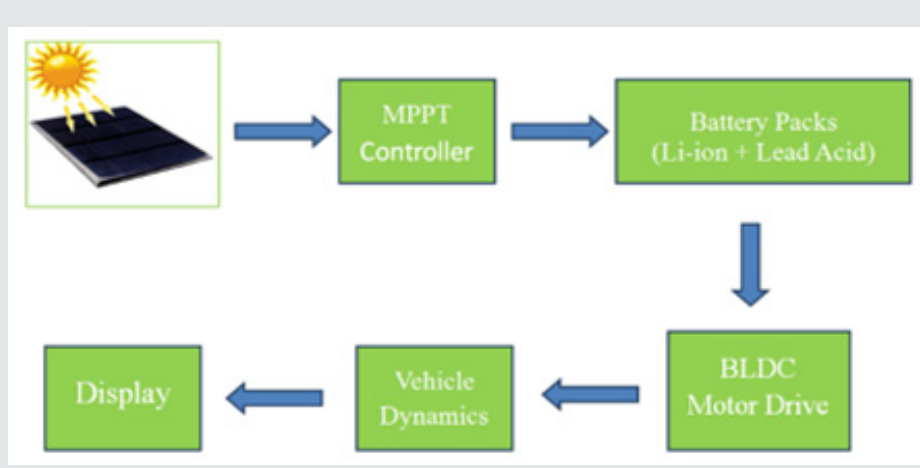

Figure 6: Block Diagram for Simulation of Solar Hybrid E-rickshaw with Heterogeneous Battery Packs.

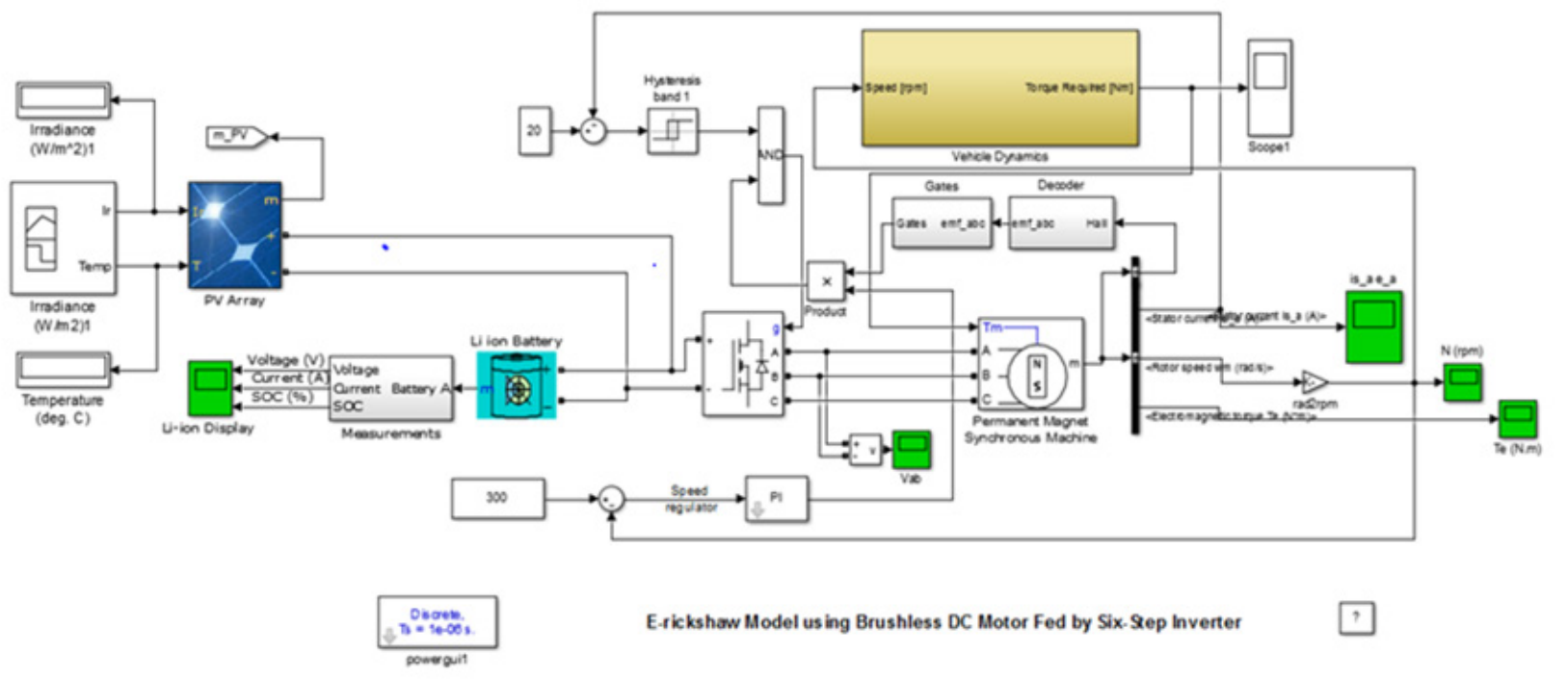

Figure 7: Solar Hybrid E-rickshaw Model with Heterogeneous Battery Packs.

\section{Results and Discussion}

\section{Solar Hybrid E-rickshaw Simulation}

Solar Hybrid E-rickshaw is simulated with Li-ion battery pack and the variations of Motor Current, battery pack Voltage, battery pack Current and State of Charge (SOC) are observed as shown in Figures 8 \& 9 .

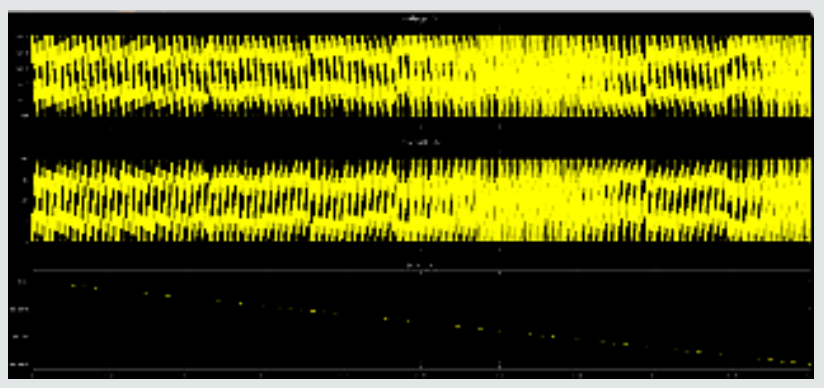

Figure 8: Li-ion battery pack Voltage, Current and State of Charge (SOC in \%).

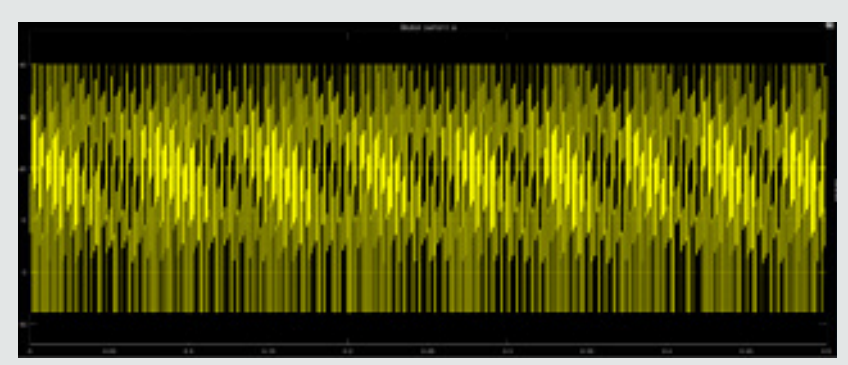

Figure 9: BLDC Stator Current.

Results for Solar Hybrid E-rickshaw Simulation with Simultaneous Heterogeneous Battery Packs. In this part the solar hybrid E-rickshaw is simulated with both Li-ion and lead acid battery packs. The variations of Battery pack State of Charge (SOC), voltage and current are observed as shown in Figures 10 \&11. The energy sharing for the simulation of solar hybrid E-rickshaw with heterogeneous batteries shows that that Li-ion battery shares higher energy during transient operating conditions. 


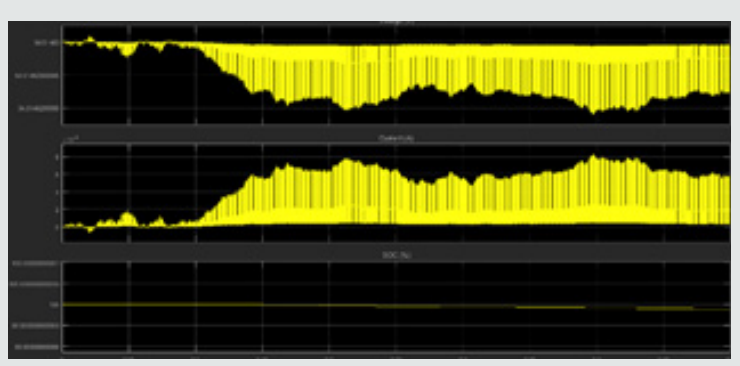

Figure 10: Li-ion battery pack Voltage, Current and State of Charge (SOC in \%).

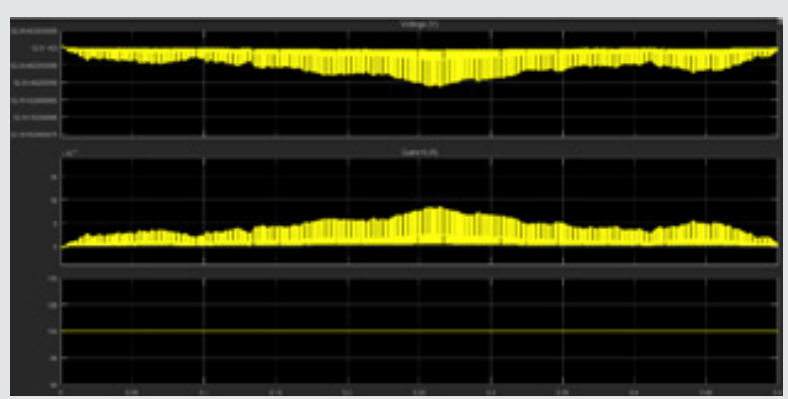

Figure 11: Lead Acid battery pack Voltage, Current and State of Charge (SOC in \%).

\section{Conclusion}

The concept of solar hybrid e-rickshaw is an important step toward sustainable green transportation system. Now-adays, government has a number of schemes for clean and green technologies and therefore solar hybrid e-rickshaw is a viable solution. In this work, E-rickshaw with solar photovoltaic panel is simulated both with single and simultaneous battery packs. It was observed from the simulation results that solar hybrid E-rickshaw with heterogeneous shows that Li-ion battery pack shares higher energy when simultaneously used with Lead acid battery pack. The results signify the possibility of implementing simultaneous battery packs at a reasonable cost price.

\section{Acknowledgment}

We sincerely thank the administration of Govind Ballabh Pant University of Agriculture \& Technology, Pantnagar for their support. The financial support from TEQIP III, College of Technology, Pantnagar is also acknowledged.

\section{References}

1. Kumar R, Saxena R, Srivastava A (2019) Modeling, Simulation and Energy-Flow Study of a Battery Electric Vehicle in Labview. 2019 IEEE International Conference on Electrical, Computer and Communication Technologies (ICECCT) p. 1-7.

2. Kumar R, Saxena R (2019) Simulation and Analysis of Switched Reluctance Motor Drives for Electric Vehicle Applications using MATLAB. 2019 4th International Conference on Electrical, Electronics, Communication, Computer Technologies and Optimization Techniques (ICEECCOT) p. 23-28.

3. Reddy KS, Aravindhan S, Mallick TK, (2017) Techno-Economic Investigation of Solar Powered Electric Auto-Rickshaw for a Sustainable Transport System. In Energies 10: 754-769.

4. Eberhard M, Terpening M (2006) The 21st Century Electric Car. Tesla Motors P. 10.

5. Enang W, Bannister C (2017) Modelling and control of hybrid electric vehicles (A comprehensive review). Renewable and Sustainable Energy Reviews 74: 1210-1239.

6. Gao DW, Mi, C, Emadi A (2007) Modeling and simulation of electric and hybrid vehicles. In Proceedings of the IEEE 95(4): 729-745.

7. Genta G (1997) Motor Vehicle Dynamics: Modeling and Simulation. Singapore, World Scientific pp.1-600.

8. Hannan MA, Azidin FA, Mohamed A (2014) Hybrid electric vehicles and their challenges: A review. Renewable and Sustainable Energy Reviews 29: $135-150$.

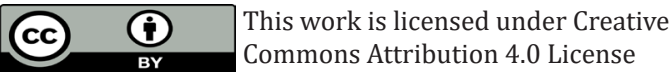

To Submit Your Article Click Here: Submit Article

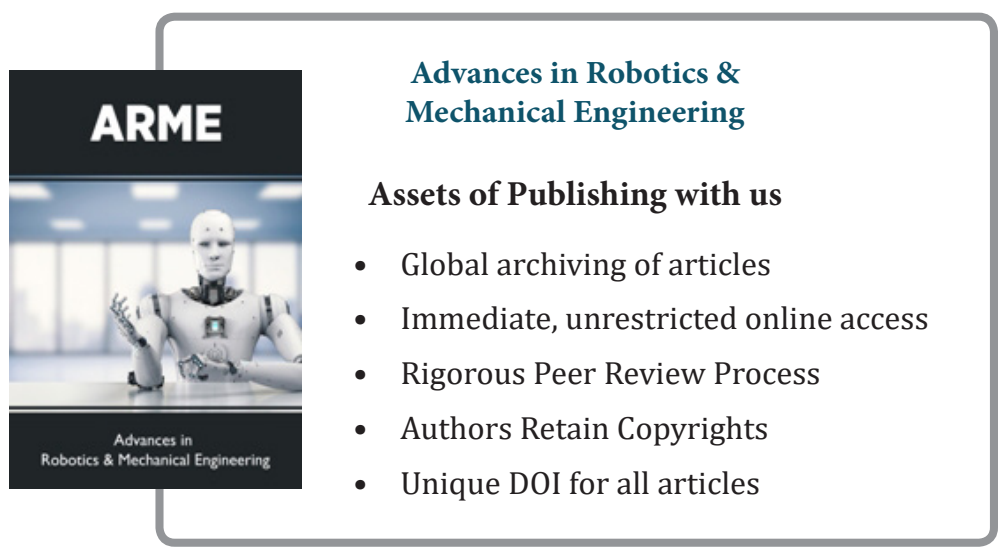

